\title{
Chemical Contamination in a Typical Independent Water Scheme (IWS) Catchment
}

\author{
T. Imo, P. Amosa, V. Vaurasi, and F. Latu
}

\begin{abstract}
Surface fresh waters including rivers, streams and lakes are a major source of drinking water and are habitats for plants and animals. Surface waters are often contaminated with chemicals such as pesticides, nutrients, heavy metals and dissolved inorganics. The sources of these chemicals include agricultural and anthropogenic activities. The occurrence of chemical contaminants in drinking water has become a problem of increasing concern. Samoa, the baseline information on the contamination problems in a typical Independent Water Scheme (IWS) catchment is very limited. Hence, this article will provide detail information on the past and current status of drinking water by chemical contaminants.
\end{abstract}

Index Terms-Catchment, drinking water, nitrate, pollutants.

\section{INTRODUCTION}

Declining drinking water quality has become a global concern due to anthropogenic activities such as agricultural activities, land development, population growth as well as climate change [1]. Drinking water comes from two basic sources: surface waters such as rivers/lakes, reservoirs and groundwater. All natural contaminants, particularly inorganic contaminants that arise from the geological strata through which the water flows and to a varying extent, anthropogenic activities by both microorganisms and chemicals [2]. Although there are natural processes such as volcanic eruptions, evaporation and condensation sometimes can cause water ground water pollution but most water pollution originates from land-based activities. Among the point sources that have the potential to contaminate ground water are agriculture, sewage disposal, solid waste disposal sites, mining, industrial processing and product storage and transportation [3]. Chemical contaminants, specifically inorganic and organic contaminants, concerning health can be present in the waters or the sources. Arsenic has been famous as an agent of death for many years and is of great health problems worldwide [4]. Heavy metals, like lead ( $\mathrm{Pb})$, copper $(\mathrm{Cu})$, chromium (IV) $(\mathrm{Cr})$ and mercury $(\mathrm{Hg})$ are dangerous for human health since they are toxic and can be carcinogenic. They have been used in a variety of electrical

Manuscript received May 22, 2019; revised September 12, 2019. (This work was supported by the Research Grants under the Water Sector of the Ministry of Natural Resources and Environment and the University Research Ethics (UREC) of the National University of Samoa.

T. Imo is with the National University of Samoa, Samoa (e-mail: t.imo@nus.edu.ws).

P. Amosa, V. Vaurasi, and F. Latu are with the Faculty of Science, National University of Samoa, Samoa (e-mail: v.vaurasi@nus.edu.ws). products and as preservatives. Fluoride is a mineral that is naturally found in drinking water and can occur in water sources from insignificant to dangerously high concentrations. At slightly higher consumption levels fluoride causes discoloration of tooth enamel and skeletal fluorosis [5]. Nitrate in drinking water is undetectable without laboratory testing because it is tasteless, odourless and colourless. Nitrates are usually present in water contaminated with septic tank sewage effluents, livestock or agricultural runoff [6]. Pesticides are widely used in modern agriculture in most countries throughout the world and in a large range of environments. Although the uses of pesticides have resulted in increased food production and other benefits [7] it has raised concerns about potential adverse health effects on human and the impact on the aquatic and coastal environment. A pesticide may also be classified as broad-spectrum when used to control a wide range of species or as narrow-spectrum when used to control a small group of species. However, the most common classification of pesticides is based on the type of pest they are used to control [8]. These include insecticides (control insects), herbicides (control weeds) and fungicides (control fungi). Pesticides are used in agriculture to maintain high production efficiency and there is a constant demand for stable crop production to support the growing human population. Pesticides are transported into aquatic systems through processes such as direct applications, surface runoffs, spray drifts, agricultural returns and groundwater intrusions; either as single chemicals or complex mixtures [9]. Mercury is a toxic heavy metal and a persistent environmental pollutant. Exposure to mercury is associated with serious adverse health and developmental effects, especially in pregnant women, developing fetuses, and young children [10]. Industrial activity results in releases of millions of pounds of mercury into the environment each year, primarily in the form of air emissions from coal-fired power plants. Mercury also is released into the environment by municipal and medical waste incineration, mining, and smelting. Once in the environment, elemental mercury can be transformed by microorganisms to organic forms, most notably methylmercury. The World Health Organization [11] and the Ministry of Health [12] in Samoa have set standards for these chemical pollutants in drinking water. In spite of the toxicity of these chemical pollutants, several studies have been conducted to evaluate and monitor their concentrations in drinking water in developing countries including Samoa. Protection of ground and surface water quality requires careful monitoring. There is a need for tighter ground and 
surface water monitoring requirements in the Water and Sanitation Sector guidelines globally and locally. Thus keeping surface free of pollution is a high priority in environment policies. The Independent Water Scheme Association (IWSA) is a Civil Society registered as an Incorporated Society (NGO). It was formed in 2007 to represent interests and support the developments of 24 independent water schemes. The IWSA was established with funding from the European Union (EU) with continued core funding being provided by the Ministry of Women Community and Social Development (MWCSD). The IWS represent and support 31 independent water schemes covering 53 villages that are not currently part of the Samoa Water Authority (SWA) network [13]. The IWS provide water to approximately $17 \%$ of the total population [14]. In Samoa, the information on the distribution and occurrence of chemical contaminants in a typical IWS drinking water is limited. This study presents a baseline data on the distribution and occurrence of potential chemical contaminants in drinking water from the selected IWS catchments in Samoa.

\section{Methodology}

\section{A. Study Sites}

This study was conducted from the selected IWS catchments (Letogo 1385'25" N, 171 ${ }^{\circ} 72^{\prime} 16^{\prime \prime} \mathrm{E}$, Aufaga $13^{\circ} 98^{\prime} 00^{\prime \prime} \mathrm{N}, 171^{\circ} 40^{\prime} 00^{\prime \prime} \mathrm{E}$; Falelatai $13^{\circ} 55^{\prime} 00^{\prime \prime} \mathrm{N}$, $171^{\circ} 59^{\prime} 00^{\prime \prime} \mathrm{E}$; (Fig. 1.). The details about sampling sites are presented in Table I.

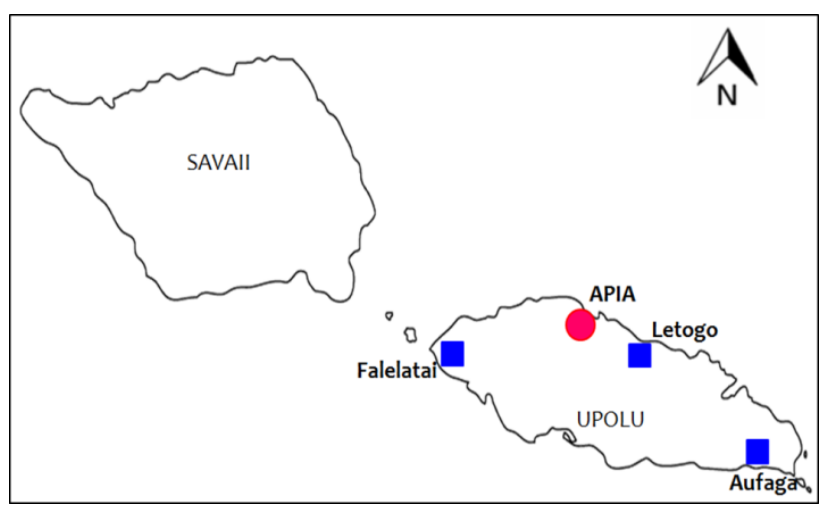

Fig. 1. Sampling locations.

TABLE I: DETAILED DESCRIPTION OF SAMPLING SITES

\begin{tabular}{lll}
\hline \hline IWS site & Samples & Possible pollution source/s \\
\hline Letogo & LT1-LT5 & Settlement/vegetation \\
Aufaga & AA1-AA5 & Vegetation/ plantation \\
Falelatai & FL1-FL5 & Vegetation/ plantation \\
\hline \hline
\end{tabular}

\section{B. Sampling and Sample Preparation}

Water samples were collected from the three IWS catchment sites during seven months of the dry season (August to October) and similarly for the wet season (November to February) in glass bottles of $1 \mathrm{~L}$ capacity. Water samples were pre-filtered through $0.45 \mu \mathrm{m}$ fiber filters (WHATMAN) to remove debris and suspended materials.

\section{Quantitative Analyses}

Pesticides (organochlorine/organophosphorus) and other chemical parameters (nitrates, phosphorus, lead, cyanide) in water samples were quantitatively determined by Gas Chromatography Mass Spectrometry (GC-MS), Atomic Absorption Spectrometry (AAS) and UV Spectrometry.

\section{Pesticides Analyses}

A $1 \mathrm{~L}$ filtered water sample from each site was extracted by liquid-liquid extraction in a separatory funnel using $n$-hexane. The combined solvent extracts were demoisturised using anhydrous granular sodium sulphate and concentrated in a rotary evaporator to a final volume of $2 \mathrm{~mL}$. All samples were analyzed for different pesticides on Gas Chromatography Mass Spectrometry (GC-MS) [15] [16].

\section{E. Nitrate Analyses}

Each sample was measured out to $150 \mathrm{~mL}$ in a volumetric flask. Then $15 \mathrm{~mL}$ of the nitrate buffer solution was added. This sample was thoroughly mixed and then added to the top of the column. The sample was collected at a rate of about 6 $\mathrm{mL}$ per 5 minutes. The first $15 \mathrm{~mL}$ of sample to come off of the column will be discarded. After collecting a fraction, 0.5 $\mathrm{mL}$ of sulfanilamide solution was added to the sample and mixed thoroughly. After 5 minutes, but not exceeding 8 minutes $0.5 \mathrm{~mL}$ of the naphthyl ethylenediamine dihydrochloride solution will be added to the fraction. After mixing, the sample developed a pink/ purple coloration. The intensity of the coloration directly related to the concentration of nitrate in the water. The sample was then analyzed with the diode array spectrophotometer, with a focus on the absorbance at the $542 \mathrm{~nm}$ wavelength [17].

\section{F. Phosphorus Analyses}

Phosphorus in river water was determined using the Ascorbic acid method. A combined liquid consisting of sulphuric acid, potassium antimonyl tartrate, ammonium molybdate and ascorbic acid was added to $25 \mathrm{~mL}$ of the water sample. This colors the sample blue in direct proportion to the amount of orthophosphate in the sample. The sample was analyzed using a UV Spectrophotometer at a wavelength of 700-880 nm [18].

\section{G. Lead Analyses}

A $100 \mathrm{~mL}$ water sample was transferred into a $250 \mathrm{~mL}$ beaker and the $\mathrm{pH}$ will be adjusted to about 3 with nitric acid. A $5 \mathrm{~mL}$ of APDC solution was added and the mixture was slowly shaken for $1 \mathrm{~min}$. The solution was passed through SDS-coated alumina packed column with the aid of a suction pump. The lead-APDC complex was absorbed in the 586 TALEBI and SAFIGHOLI column. The column was washed with $10 \mathrm{~mL}$ distilled de-ionized water. The lead complex was finally eluted from the column by washing with $4.5 \mathrm{~mL}$ of nitric acid (4M). The eluent were collected in a $5 \mathrm{~mL}$ volumetric flask and made to the volume with distilled de-ionized water. A Varian atomic absorption spectrometer, Model AA-220, equipped with a deuterium background correcting system was used for the determination of the lead concentration [19]. 


\section{H. Statistical Analyses}

The Statistical Package for Social Sciences (SPSS) was used for all statistical calculations such as determination of basic statistical parameters (mean, geometric mean, median, maximum, minimum variance and standard deviations) for all the data from the three sites. All tests were performed at least twice to calculate the average value.

\section{RESULTS}

The mean $\mathrm{pH}$ of the investigated samples ranged from 7.12 to 7.25 indicates that all water samples are slightly alkaline. The mean temperature variations at different IWS ranged from $18.5^{\circ} \mathrm{C}$ to $20.8^{\circ} \mathrm{C}$. The mean concentrations of the different chemical contaminants are shown in Table IV and Table V.

TABLE II: WHO GUIDELINE STANDARDS (DRINKING WATER QUALITY) 2010

\begin{tabular}{lc}
\hline \hline Chemical contaminants & Limited Level (mg/L) \\
\hline Lead & 0.01 \\
Iron & 0.30 \\
Arsenic & 0.01 \\
Mercury & 0.006 \\
Copper & 2.0 \\
Fluoride & 1.50 \\
Chloride & 250 \\
Pesticides/Herbicides & $<0.01$ \\
Nitrates & 50 \\
\hline \hline
\end{tabular}

TABLE III: MOH GUIDELINE STANDARDS (DRINKING WATER QUALITY) -

\begin{tabular}{lc}
\hline \multicolumn{2}{c}{2008} \\
\hline \hline Chemical contaminants & Limited Level (mg/L) \\
\hline Lead & 0.01 \\
Iron & 0.30 \\
Arsenic & 0.01 \\
Mercury & 0.001 \\
Copper & 1.0 \\
Fluoride & 1.5 \\
Chloride & 250 \\
Pesticides/Herbicides & $0.001-0.04$ \\
Nitrates & 50 \\
\hline \hline
\end{tabular}

TABLE IV: MEAN CONCENTRATIONS OF DETECTED CONTAMINANTS

\begin{tabular}{|c|c|c|c|c|}
\hline \hline \multirow{5}{*}{ IWS sites } & Samples & Nitrate & Fluoride & Chloride \\
\hline \multirow{5}{*}{ Falelatai } & FL1 & $1.20 \pm 0.01$ & $0.41 \pm 0.01$ & $15 \pm .0 .44$ \\
& FL2 & $1.21 \pm 0.04$ & $0.42 \pm 0.01$ & $15 \pm 0.42$ \\
& FL3 & $1.20 \pm 0.02$ & $0.45 \pm 0.01$ & $15 \pm 0.40$ \\
& FL4 & $1.20 \pm 0.01$ & $0.40 \pm 0.01$ & $15 \pm 0.39$ \\
& FL5 & $1.20 \pm 0.02$ & $0.32 \pm 0.01$ & $15 \pm 0.24$ \\
\hline \multirow{5}{*}{ Aufaga } & AA1 & $1.50 \pm 0.11$ & $0.49 \pm 0.01$ & $15 \pm 0.14$ \\
& AA2 & $1.51 \pm 0.11$ & $0.47 \pm 0.02$ & $15 \pm 0.14$ \\
& AA3 & $1.70 \pm 0.31$ & $0.47 \pm 0.02$ & $15 \pm 0.25$ \\
& AA4 & $1.70 \pm 0.31$ & $0.47 \pm 0.02$ & $15 \pm 0.96$ \\
& AA5 & $1.70 \pm 0.22$ & $0.49 \pm 0.01$ & $15 \pm 0.26$ \\
& & & & $11 \pm 0.54$ \\
& LT1 & $1.40 \pm 0.12$ & $0.43 \pm 0.08$ & $11 \pm 0.54$ \\
& LT2 & $1.40 \pm 0.12$ & $0.49 \pm 0.03$ & $11 \pm 0.15$ \\
& LT3 & $1.90 \pm 0.38$ & $0.59 \pm 0.03$ & $11 \pm 0.24$ \\
& LT4 & $1.90 \pm 0.41$ & $0.59 \pm 0.03$ & $11 \pm 0.19$ \\
\hline \hline
\end{tabular}

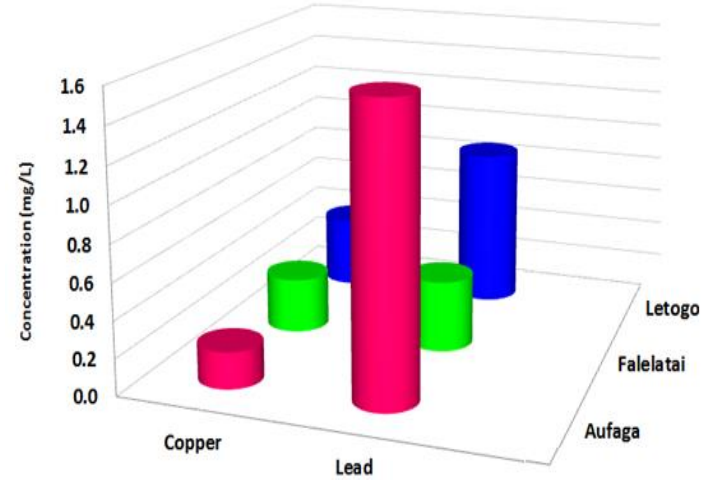

Fig. 2. Concentrations of copper \& lead, August.

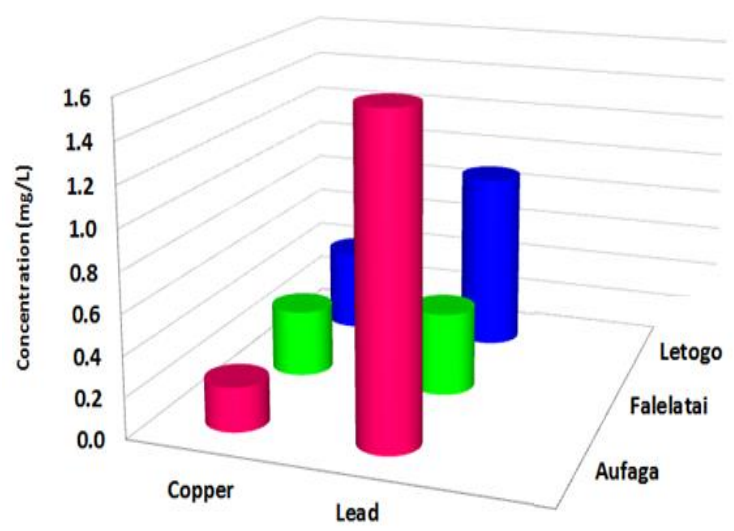

Fig. 3. Concentrations of copper \& lead, September.

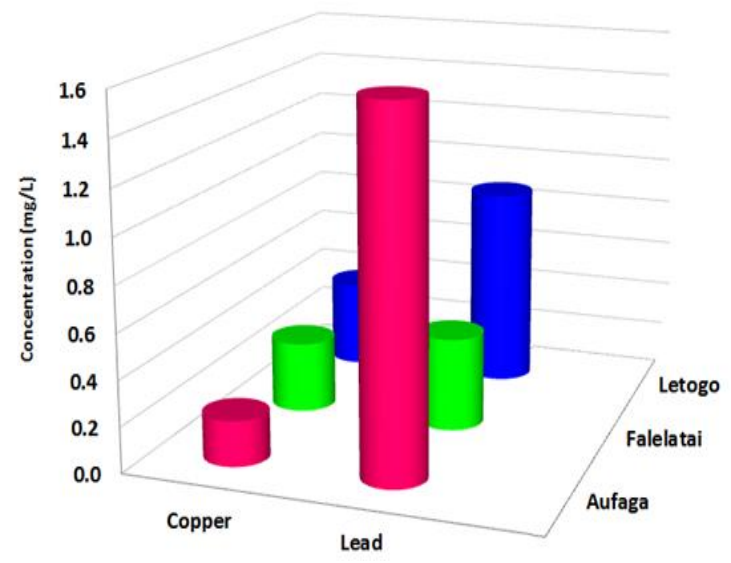

Fig. 4. Concentrations of copper \& lead, October.

TABLE V: MEAN CONCENTRATIONS OF DETECTED CONTAMINANTS

\begin{tabular}{|c|c|c|}
\hline \hline \multicolumn{1}{|c}{ Samples } & Phosphorus \\
\hline \multirow{5}{*}{ Falelatai } & FL1 & $0.18 \pm 0.05$ \\
& FL2 & $0.17 \pm 0.05$ \\
& FL3 & $0.18 \pm 0.05$ \\
& FL4 & $0.18 \pm 0.04$ \\
& FL5 & $0.18 \pm 0.04$ \\
\hline \multirow{5}{*}{ Aufaga } & AA1 & $0.16 \pm 0.05$ \\
& AA2 & $0.16 \pm 0.05$ \\
& AA3 & $0.18 \pm 0.04$ \\
& AA4 & $0.18 \pm 0.04$ \\
& AA5 & $0.16 \pm 0.05$ \\
\hline \multirow{5}{*}{ Letogo } & LT1 & $0.19 \pm 0.01$ \\
& LT2 & $0.19 \pm 0.04$ \\
& LT3 & $0.19 \pm 0.01$ \\
& LT4 & $0.19 \pm 0.01$ \\
& LT5 & $0.19 \pm 0.01$ \\
\hline
\end{tabular}




\section{DISCUSSION}

The chloride concentration ranges from 11 to $15 \mathrm{mg} / \mathrm{L}$ indicates the possible sources can be from the accumulation of chlorine in the water pipes. Similarly, the concentration of fluorides is in the ranges of 11 to $15 \mathrm{mg} / \mathrm{L}$. The increase in concentration ranged from 1.20 to $1.90 \mathrm{mg} / \mathrm{L}$ for nitrate and the highest concentration was detected at the Letogo IWS. It was suggested that this could be due to the runoff from nearby settlements. The highest concentration of phosphorus was $0.19 \mathrm{mg} / \mathrm{L}$ (Letogo IWS) followed by $0.18 \mathrm{mg} / \mathrm{L}$ (Falelatai and Aufaga). It was suggested that the source of phosphorus could be from agricultural activities. There were no pesticides and mercury detected from all three IWS. This suggests that crop plantations surrounding the catchments had used other alternatives instead of pesticides. For the heavy metals, the highest concentration of lead was detected at the Falelatai IWS $(0.29 \mathrm{mg} / \mathrm{L})$ followed by $0.28 \mathrm{mg} / \mathrm{L}$ from Letogo IWS. The possible sources could be from past usage of lead based paints in the catchment or soil containing pesticides that were used near the catchment decades ago. The highest concentration of lead was found in the first three months of sampling from the Aufaga site followed by Letogo and Falelatai sites (Figures 2, 3, 4). On the other hand, the concentration of copper was in the ranges of 0.11 to 1.39 $\mathrm{mg} / \mathrm{L}$. All the concentrations are below the WHO and the MoH standards (Tables II \& Table III) except for lead; however long term exposure of these chemical contaminants might have detrimental impacts on human health and the environment as well. Further monitoring studies are needed on the analysis of chemical contaminants in the IWS catchments seems unlikely to advance our knowledge of the occurrence and the sources of these contaminants in the IWS catchments.

\section{CONCLUSION}

This paper describes a monitoring survey carried out in the three selected IWS catchments to evaluate the physical-chemical quality of drinking water supply by the IWS to the three villages. This research provided a baseline water quality data for the IWS catchments in Samoa. The analyses of chemical contaminants in IWS systems are commonplace for drinking water to ensure compliance with regulatory limits. The results from this survey will provide more insight to chemical contaminants which is a necessary objective in minimizing the exposure to these contaminants in drinking water.

\section{CONFLICT OF INTEREST}

The authors declare no conflict of interest.

\section{AUTHOR CONTRIBUTIONS}

T.Imo wrote the paper and conducted chemical analyses; P.Amosa analysed the data, V.Vaurasi and F.Latu conducted sampling collection and field activities. All authors had approved the final version.

\section{ACKNOWLEDGMENT}

This research was supported by the Research Initiative under the Water Sector Division of the Ministry of Natural Resources and Environment, Government of Samoa and the University Research Ethics Committee (UREC) of the National University of Samoa. We thank Leiataualesa Tofae Alailima Nuualiitia and Kadiravelu Suthakar of the IWSA for their assistance and support.

\section{REFERENCES}

[1] C. J. Wyatt et al., "Incidence of heavy metal contamination in water supplies in Northern Mexico," Environmental Research, vol. 762, pp. 114-119, 1998.

[2] EPA: Drinking Water Contaminants, 2015.

[3] J. K. Fawell and G. Standfield, "Drinking water quality health," Pollution: Causes, Effects and Control, London: Royal Society of Chemistry, 2001.

[4] P. Feldman et al., "Assessment of the chemical quality of drinking water in Cambodia," J. Water Health, vol. 5, pp. 101-116, 2007.

[5] WHO: World Health Organisation, WHO Guidelines for Drinking-Water Quality, Fluoride in Drinking-Water, 2004.

[6] M. Miyamoto, H. Tanaka, and T. Katagi, "Ecotoxicological risk assessment of pesticides in aquatic ecosystems," SUMITOMO KAGAKU, vol. 1, pp. 1-18, 2008.

[7] E. Kim, J. C. Little, and N. Chiu, "Estimating exposure to chemical contaminants in drinking water," Environ. Sci. Technol., vol. 36, no. 6 , pp. 1799-1806, 2004.

[8] A. Naik and A. Wanganeo, "Occurrence of some pesticides in bhoj wetland bhopal and their effect on phytoplankton community: An ecological perspective," Journal of Toxicology and Environmental Health Science, vol. 6, no. 9, pp. 170-180, 2014.

[9] F. Gashi et al., "Evaluation of the chemical and microbiological contamination of the river sitnica waters (Kosovo): A statistical approach," Env. Chem. Bull, vol. 4, no. 10, pp. 463-467, 2015.

[10] M. A. El-Shafy and A. Grünwald, "THM formation in water supply in South Bohemia, Czech Republic," Water Research, vol. 34, no. 13, pp. 3453-3459, 2000.

[11] WHO: World Health Organization, Guidelines for Drinking-water Quality, 2011

[12] MoH: Ministry of Health, Government of Samoa, Guidelines for Drinking water Quality, 2008.

[13] Water and Sanitation Sector, Samoa, Water \& Sanitation Sector Plan 2012-2016.

[14] IWSA: Independent Water Schemes in Samoa, 2010.

[15] APHA, AWWA and WEF, Standard Method for the Examination of Water and Waste Water, $20^{\text {th }}$ ed. Am. Pub. Health. Ass. Washington D.C., 1998.

[16] I. S. Imo et al., "The comparative study of Trihalomethanes in drinking water," International Journal of Environment Science and Technology, vol. 4, no. 4, pp. 421-426, 2007.

[17] U.S. Environmental Protection Agency, Drinking Water Standards and Health Advisories, Government Printing Office, Washington, DC, USA, 2012.

[18] A. M. Fan, "Nitrate and nitrite in drinking water: A toxicological review," Encyclopedia of Environmental Health, pp. 137-145, 2011.

[19] J. E. Marcovecchio et al., "Heavy metals, major metals, trace Elements," Handbook of Water Analysis, pp. 275-311, CRC Press, London, UK, 2007.

Copyright (C) 2019 by the authors. This is an open access article distributed under the Creative Commons Attribution License which permits unrestricted use, distribution, and reproduction in any medium, provided the original work is properly cited (CC BY 4.0).

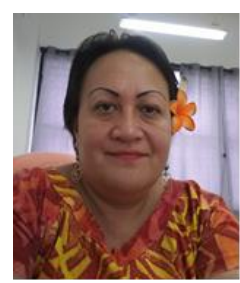

Taema Imo is the associate professor in environmental science in the Faculty of Science. She is the expert in environmental pollution in Samoa. Her research is geared towards environmental and marine pollution, management and toxicology. 


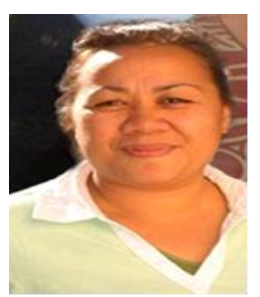

Patila Amosa is the dean of the Faculty of Science and senior lecturer. She is the expert in climate change in Samoa. Her research interests are in the areas of marine pollution and oceanography.

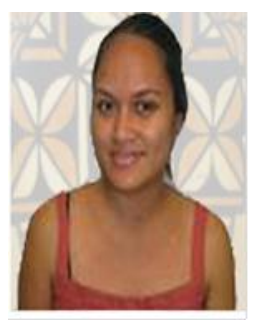

Varea Vaurasi is the senior science lab technician of the National University of Samoa. Her research interests are in the areas of agrochemicals and pollution.

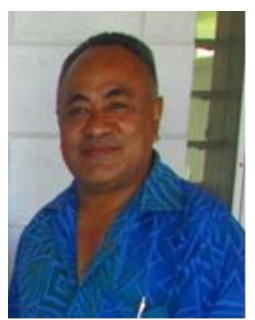

Faainu Latū is the head of the Science Department of the Faculty of Science. He has been intensively involved in various environmental projects with the Ministry of Natural Environment in Samoa and also with regional organization such as SPREP and international universities. 